\title{
A Comparison of the Particulate Feeding Abilities of Three Species of Gorgonian Soft Coral
}

\author{
Howard R. Lasker* \\ Rosenstiel School of Marine and Atmospheric Sciences, University of Miami, 4600 Rickenbacker Causeway, Miami, Florida
} 33149 , USA

\begin{abstract}
Particulate feeding abilities of Briarium abestimum, Pseudoplexaura porosa and Pseudopterogorgia americana were measured from in situ and flow tank experiments. Although these species do not readily capture naturally occurring zooplankton they can capture and ingest particulate matter (Artemia cysts). Suspension feeding capabilities of the three are ranked $P$. porosa $>P$. americana $>B$. abestinum. Variance in feeding between polyps, branches, and even colonies of the same species is high. In flow tank experiments polyps on the downstream side of $B$. abestinum colonies had greater capture rates than upstream polyps. The inability to capture zooplankton and the effect of polyp position on particle capture is believed to be a consequence of low densities of nematocysts among these three species.
\end{abstract}

\section{INTRODUCTION}

Most anthozoans may be characterized as carnivores which capture prey using specialized cells, the nematocysts. In fact, many anthozoans, particularly reef dwellers, are capable of utilising additional food sources. The most notable of these is the use of photosynthate from symbiotic zooxanthellae (Muscatine and Hand, 1958). Bacteria (Disalvo, 1971), dissolved organic matter (Stephens, 1962), and particulate matter (Lewis and Price, 1976) have also been implicated as potential food sources. It is likely that any single species utilizes a number of these food sources. Therefore, attempts to characterize anthozoan energy budgets, particularly those comparing the use of photosynthate to other sources, must consider many different modes of feeding. In this study I report on the potential importance of particulate feeding by three species of gorgonian soft coral.

Among corals the large contribution of the zooxanthellae and readily observable zooplankton captured by polyps has overshadowed the significance of suspension feeding. However, corals do form mucus nets which can capture particulate matter (Lewis and Price, 1976) and both Roushdy and Hansen (1961) and Lewis

\footnotetext{
- Present address: Department of Biological Sciences, State University of New York at Buffalo, Buffalo, New York 14.260, USA
}

(1976) have demonstrated that corals are capable of removing suspended particulate matter from the water column.

The available data suggest that feeding on suspended particulates may be especially important among gorgonians. Although capture of zooplankton like Artemia nauplii has been observed in laboratory experiments (Leversee, 1976), field observations (Lasker, unpubl.) indicate that in most instances zooplankters striking gorgonian tentacles swim away unaffected. Furthermore, Mariscal and Bigger (1977) report that ingested Artemia nauplii are frequently regurgitated whole. Mariscal and Bigger also point out that the cnidom of both Leptogorgia virgulata and Renilla mulleri has fewer numbers and types of nematocysts than the scleractinian Balanophyllia elegans.

Despite their low nematocyst densities and relative inability to utilise zooplankton, gorgonians are capable of capturing and assimilating particulate matter. Roushdy and Hansen (1961) showed that Alcyonium digitatum is able to filter diatoms (Skeletonema costatum) from the water and to ingest them, and Murdock (1978) has demonstrated ingestion, digestion and assimilation of animal tissue (rat livers) placed on polyps' tentacles.

Among hermatypic species, which contain zooxanthellae, reduced zooplankton feeding may imply increased reliance on the zooxanthellae and may not 
be indicative of an increased role for suspension feeding. However, Mariscal and Bigger (1977) worked with ahermatypic species. Reduced zooplankton feeding by these species necessitates some other form of feeding like suspension feeding (or, as they suggest, uptake of dissolved organic matter).

Particulate feeding enables gorgonians to utilise non-motile suspended particulate matter. Plant and animal detritus make up a large fraction of suspended particulate matter on reefs (Johannes et al., 1970; Glynn, 1972), and this material may be an excellent food source due to microbial populations inhabiting the particles (Fenchel, 1973). Additionally, mucus flocs, which are also of high nutritional quality (Ducklow, 1979a, b) are common in reef waters (Johannes, 1967; Marshall, 1967; Rublee et al. 1980). The capture of non-motile particulate matter is, therefore, a feeding mechanism of potential value to gorgonians.

\section{MATERIAL AND METHODS}

The feeding capabilities of 3 gorgonian species were determined. Briarium abestinum (Pallas), a common gorgonian of all reef habitats, forms short $(<50 \mathrm{~cm})$ branches, joined at a common base. The polyps have long ( $>5 \mathrm{~mm}$ ) pinate tentacles which are continuously expanded. Colonies of $B$. abestinum were studied in situ at Crawl Cay near Bocas del Toro, Panama and at Churchill Beach, Grand Bahama Island.

Pseudopterogorgia americana (Gmelia) is a common gorgonian of shallow water patch reef environments. The species grows as large arborescent colonies up to $1 \mathrm{~m}$ in height. Polyps are small with short $(\approx 2 \mathrm{~mm})$, stubby tentacles. Polyps are characteristically contracted at night. Experiments on $P$. americana were conducted at Churchill Beach, Grand Bahama Is.

Pseudoplexaura porosa (Houttuyn) is a large (>2 m) arborescent gorgonian found in shallow water back reef environments. Its polyps are large with long $(\approx$ $5 \mathrm{~mm})$, pinate tentacles. Polyps are expanded day and night. Two colonies of $P$. porosa were examined on a small patch reef off Nalu Nega in the San Blas Is., Panama. These colonies will be referred to as $P$. porosa $A$ and $P$. porosa $B$.

The ability of these species to feed on naturally occurring zooplankton was determined by exposing colonies to dense swarms of zooplankton attracted to dive lights at night. Carefully holding a dive light about $15 \mathrm{~cm}$ from a colony exposed polyps on the near branches to exceptionally high concentrations of zooplankton. After a $5 \mathrm{~min}$ exposure to the plankton swarm, the light was removed and several $10 \mathrm{~cm}$ branch tips cut from the colony. These were immediately sealed in plastic bags and preserved by injecting formalin into the bag. Removal of the branch tip and preservation required less than 1 min and branch tips were frequently preserved with their polyps still expanded. A control sample was collected prior to illumination

Feeding was detected by determining numbers of prey in the guts of 20 randomly selected polyps. Polyps were carefully dissected and the gut examined at $40 \mathrm{X}$

Particulate feeding was evaluated by measuring ingestion of Artemia cysts presented to branch tips in an in situ chamber. The chamber (Fig. 1) is modified from the design of Gust (1977), and consists of a polyethelene bag held open at the base by a Plexiglas frame. The base is placed over branch tips attached to PVC piping and is held flush against the sand bottom with lead weights. The top of the bag is held in position by a Plexiglas disc and styrofoam float. The chamber is $30 \mathrm{~cm}$ in diameter, $35 \mathrm{~cm}$ high and when placed over the bottom traps approximately 25 I of water There are no rigid components connecting the base to the top of the chamber and both the top and sidewalls oscillate as a function of water movement. Gust (1977) reports that water movement within such a chamber closely approximates natural conditions.

Two series of particulate feeding experiments were conducted on the colonies of Pseudoplexaura porosa at Nalu Nega. In the first, 18 branch tips from a single colony ( $P$. porosa A) were attached to PVC piping with cable ties. The branches were arranged into 3 groups of 6 branch tips each and were allowed to acclimate for $24 \mathrm{~h}$. After the acclimation period chambers were carefully placed over each of the 3 groups. Polyps of all the branches were fully expanded both prior to and immediately after the chambers were emplaced. Artemia cysts $\left(2 \mathrm{~cm}^{3}\right)$ were then injected into each chamber and the colonies allowed to feed for $15 \mathrm{~min}$. At the end of the experiment the branches were removed and preserved as described above. The number of ingested cysts in 20 polyps per branch were determined by dissection.

The second set of experiments compared branch tips from the two colonies of Pseudoplexauera porosa. On each of $3 d, 3$ branch tips from each of the colonies were removed and attached to PVC pipes with cable ties. One branch from each colony was attached to the same pipe. After $24 \mathrm{~h}$ a chamber was lowered over each of the paired branch tips and $2 \mathrm{~cm}^{3}$ of cysts injected. The colonies were allowed to feed for $15 \mathrm{~min}$. Nine paired samples were collected in this manner.

At Churchill Beach pairwise experiments of Briarium abestinum and Pseudopterogorgia americana were conducted following the procedure described above. In these experiments the acclimation period was reduced to $4 \mathrm{~h}$, with no visible effect on behavior of the branch tips. Analysis of the Briarium-Pseudop- 


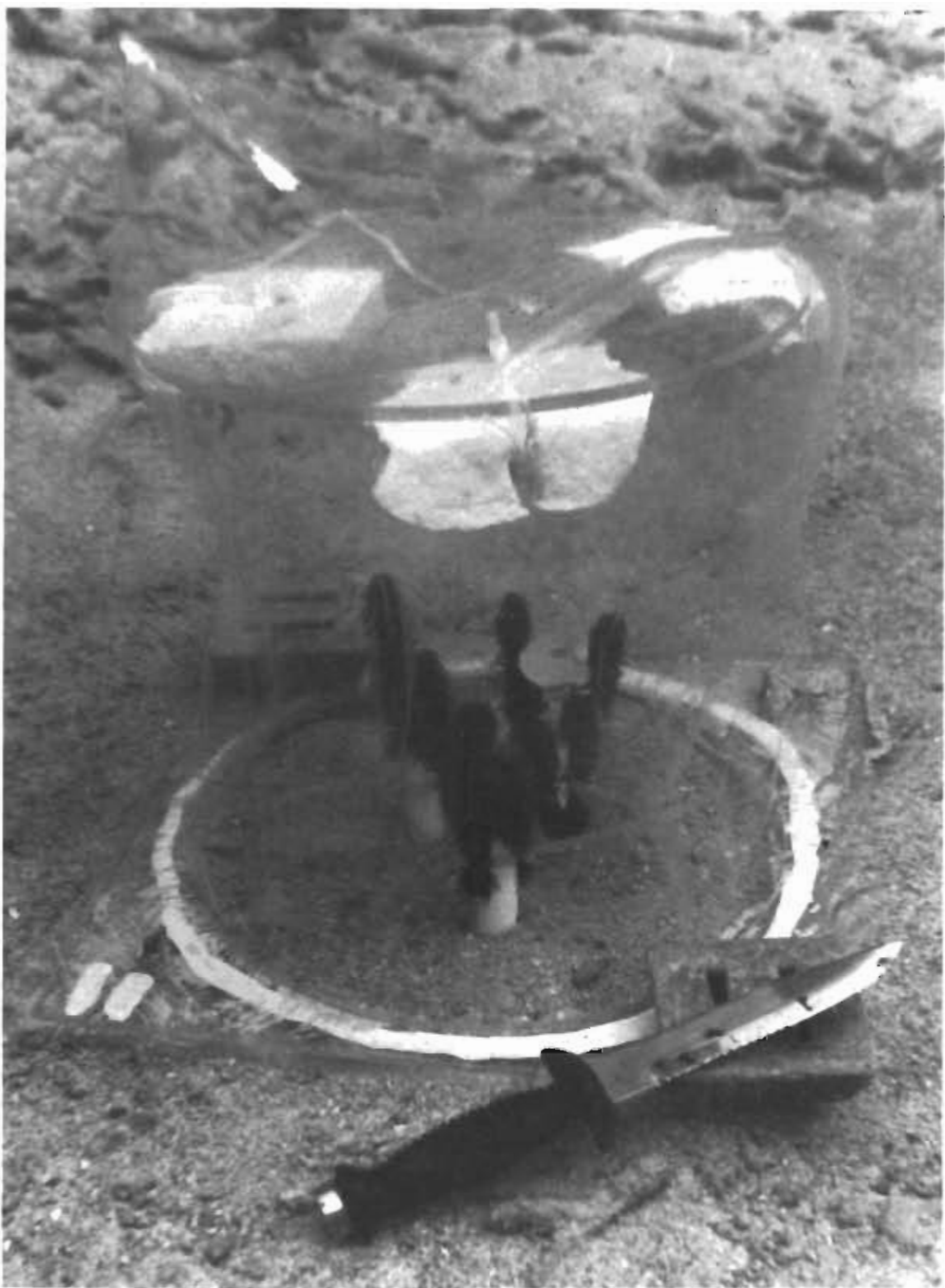

Fig. 1. Feeding chamber with branch tips of Briarium abestinum enclosed within

terogorgia comparison is based on examination of 40 polyps from each branch tip.

The chambers used in the in situ experiments cannot be used in areas of strong currents or wave action. Two of the species examined in this report, Briarium abestinum and Pseudopterogorgia americana, are commonly found in areas of rapid water movement. In order to examine feeding in high-current environments, colonies of $B$. abestinum were fed Artemia cysts in a flow tank at current speeds of 3.5 and $7.3 \mathrm{~cm} \mathrm{~s}^{-1}$.

The flow tank used is elliptical, holds $30 \mathrm{l}$, and is similar in design to that described by Leversee (1977). A Plexiglas partition was used instead of straws to reduce turbulence. Colonies used in the experiments were collected from Triumph Reef in the Florida Keys and were maintained in flowing sea water at the Rosenstiel School of Marine and Atmospheric Sciences.

Colonies were placed in the flow chamber 2-4 h prior to the start of the experiment. Two colonies were usually tested simultaneously. After polyps on the branches were expanded $0.15 \mathrm{~g}$ (approximately 0.35 $\mathrm{cm}^{3}$ ) of Artemia cysts were added and the colonies allowed to feed for either 15 or $60 \mathrm{~min}$. At the end of the experiment the upstream side of the branch was notched and the colony preserved. Twenty polyps were dissected from the midline of both the up and downstream side and the number of ingested Artemia cysts determined.

\section{RESULTS}

Pseudopterogorgia americana colonies were contracted at night. Therefore, night illumination experiments were only conducted on Briarium abestinum and Pseudoplexaura porosa. Polyps of both species reacted rapidly to the dense zooplankton swarms attracted by the dive lights. Zooplankters frequently came into contact with polyps invoking a rapid contraction of the polyp. This reaction is similar to that 
observed when polyps capture prey, but careful examination of these events indicated that the zooplankter involved invariably escaped from the contracting polyp. Twenty polyps from each of $2 \mathrm{~B}$. abestinum and $3 P$. porosa colonies were examined and in all cases, their guts were empty. A single copepod exoskeleton was found in 1 of the $P$. porosa control samples. No prey were found in the $B$. abestinum controls.

Polyps of all 3 species actively fed on Artemia cysts. Reaction to the cysts was rapid and frequently resulted in polyp contraction as described above. However, in this case particles were regularly found in the gut.

Results of the first series of Nalu Nega experiments are presented in Table 1 . In these experiments 18

Table 1. Pseudoplexaura porosa. Mean number of ingested Artemia cyst/polyp in branches from 3 replicate experiments. Twenty polyps were sampled from each branch

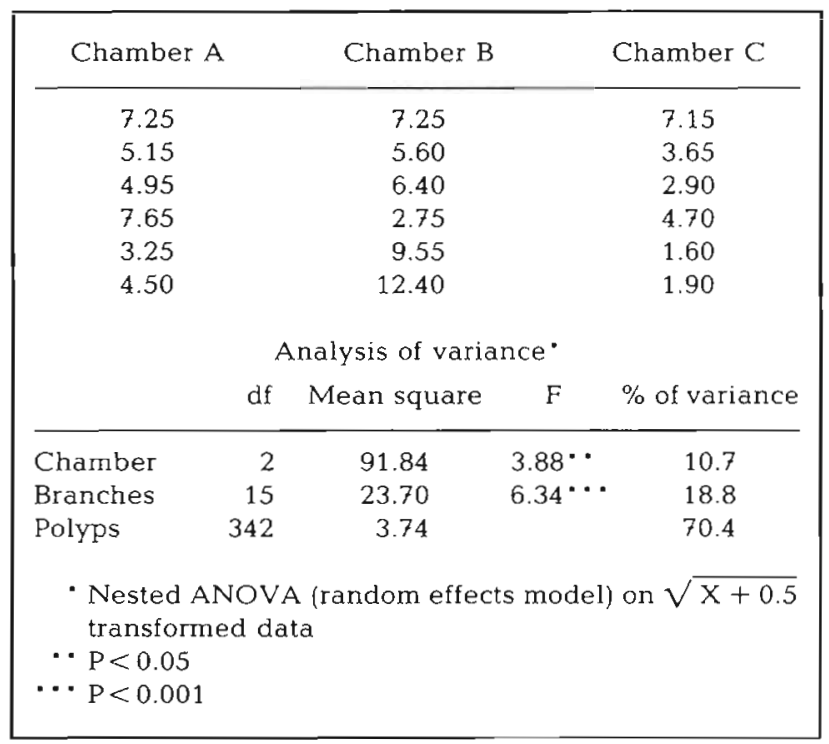

branches from the same colony were simultaneously tested in 3 experimental chambers. The number of cysts ingested by any single polyp proved to be highly variable and accounted for the largest portion of the total variance. Variance in number of ingested cysts among polyps from the same branch was closely correlated to the mean number ingested for the branch $(r=$ $0.74, P<0.001)$, but the distribution of numbers of cyst/ polyp does not fit Poisson expectations among any of the 18 branches $\left(\chi^{2}-\right.$ test of $\left.S^{2} / \bar{X}\right)$. Despite the large among polyp variance significant differences between branches and between chambers were found. These effects are evident in the means presented in Table 1. Significant differences are found despite the fact that the branches were all from the same colony and were tested simultaneously in identical chambers.

Variation between polyps and failure of the number of captured cysts to fit a Poisson function indicates either differential supply over the length of the branch or differential feeding ability. Similarly, differences between branches may be attributed to either supply effects or actual differences in feeding ability. Although the question of supply cannot be ignored, every attempt was made to insure a uniform distribution of the cysts. They were injected from the base of the chamber and directed up and away from the branches. The cloud of cysts which formed dispersed within $60 \mathrm{~s}$. It is likely that the dispersion accounts for much of the between branch variance. However, the proximity of polyps on the same branch makes such an explanation less likely when examining among polyp variation. Variation between chambers is interpreted as an experimental artifact due perhaps to small differences in cyst density and dispersion.

Variance among polyps and between chambers is again evident in the pairwise comparison of colonies Pseudoplexaura porosa A and P. porosa B (Table 2). Among polyp and between chamber effects account for over $60 \%$ of the total variance in these experiments. Only a single branch from each colony was used in a chamber and it is impossible therefore to partition a branch effect, but much of the branch effect should be present in the interaction term, which is significant. Despite the similarities in form between these two colonies there is a significant colony effect, $P$. porosa $A$ ingesting more cysts than $P$. porosa $\mathrm{B}$. Once again this difference is discerned against a background of enormous lower level variation. In this case, the pairwise experimental procedure allows for a 2 -way analysis of variance. If the colonies had not been paired a nested analysis of variance would have been used and in this

Table 2. Pseudoplexaura porosa. Mean numbers of ingested Artemia cysts/polyp in branches from 2 colonies. Nine replicate pairwise experiments are presented

\begin{tabular}{|c|c|c|c|c|c|c|c|c|c|}
\hline \multicolumn{10}{|c|}{ Chamber } \\
\hline Species & 1 & 2 & 3 & 4 & 5 & 6 & 7 & 8 & 9 \\
\hline P. porosa A 1 & 13.75 & 0.20 & 1.80 & 6.151 & 1.60 & 1.65 & 6.90 & 12.65 & 4.0 \\
\hline P. porosa B & 10.30 & 8.60 & 1.45 & 4.452 & 2.60 & 2.45 & 0.85 & 2.70 & 1.5 \\
\hline \multicolumn{10}{|c|}{ Analysis of variance } \\
\hline & $\mathrm{d} \mathbf{f}$ & $\mathrm{Me}$ & an sq & uare & & F & \multicolumn{3}{|c|}{$\%$ of variance } \\
\hline Groups & 17 & & 15.42 & & & & & & \\
\hline Colony & 1 & & 30.96 & & & $51 \cdots$ & & 12.6 & \\
\hline Chamber & 8 & & 22.04 & & 20.8 & $80^{\cdots}$ & & 20.7 & \\
\hline Interaction & 8 & & 6.86 & & & $48^{\cdots}$ & & 32.2 & \\
\hline Polyps & 342 & & 1.06 & & & & & 41.8 & \\
\hline \multicolumn{10}{|c|}{$\begin{aligned} & \text { 2-way ANOVA (mixed model) of } \sqrt{\mathrm{X}+0.5} \\
& \text { transformed data } \\
\cdots & P<0.005 \\
\cdots & P<0.001\end{aligned}$} \\
\hline
\end{tabular}


case the species difference would not be recognized as being significant.

Results of the Pseudopterogorgia americana and Briarium abestinum comparisons are presented in Table 3 . The results are quite similar to those of the

Table 3. Briarium abestinum and Pseudopterogorgia americana. Mean numbers of ingested Artemia cysts/polyp for colonies tested simultaneously

\begin{tabular}{|c|c|c|c|c|c|c|}
\hline \multicolumn{7}{|c|}{ Chamber } \\
\hline Species & 1 & 2 & 3 & 4 & 5 & 6 \\
\hline B. abestinum & 0.55 & 0 & 2.90 & 0.45 & 1.20 & 0.25 \\
\hline P. americana & 1.75 & 2.05 & 2.50 & 0.95 & 3.43 & 2.90 \\
\hline \multicolumn{7}{|c|}{ Analysis of variance } \\
\hline & df $\mathrm{Me}$ & ean squ & are & $\mathrm{F}$ & \multicolumn{2}{|c|}{$\%$ of variance } \\
\hline Groups & 11 & 4.15 & & & \multirow{2}{*}{\multicolumn{2}{|c|}{16.2}} \\
\hline Species & 1 & 14.06 & \multicolumn{2}{|c|}{$8.34^{*}$} & & \\
\hline Chamber & 5 & 4.63 & \multicolumn{2}{|c|}{$13.07^{\cdots}$} & \multicolumn{2}{|c|}{16.8} \\
\hline Interaction & 5 & 1.69 & \multirow{2}{*}{\multicolumn{2}{|c|}{$4.76^{\cdots}$}} & \multicolumn{2}{|c|}{10.5} \\
\hline Polyps & 228 & 0.36 & & & & 6.6 \\
\hline \multicolumn{7}{|c|}{$\begin{aligned} & \text { 2-way ANOVA (mixed model) of } \sqrt{\mathrm{X}+0.5} \\
& \text { transformed data } \\
\cdots & \mathrm{P}<005 \\
\cdots & \mathrm{P}<.001\end{aligned}$} \\
\hline
\end{tabular}

previous experiments. Between polyp and chamber effects account for most of the total variance. However, a significant species effect is also evident, $P$. americana ingesting more cysts than $B$. abestinum. The in situ experiments using Artemia cysts demonstrate the ability of these gorgonian species to capture and ingest suspended particulate matter. Furthermore, differences in feeding capabilities - even among colonies of the same species - are evident in pairwise comparisons. In an effort to compare the results from both sets of experiments the results were analysed in a stepwise test procedure using the Mann-Whitney U statistic (Sokal and Rohlf, 1969). Those results in combination with the ANOVAs of Tables 2 and 3 indicate the feeding abilities of these 4 species may be ranked as $P$. porosa $\mathrm{A}>P$. porosa $\mathrm{B} \approx P$. americana $>B$. abestinum.

Mean numbers of ingested cysts from the flow tank experiments are presented in Table 4. The density of cysts in these experiments was approximately $20 \%$ lower than in the in situ chamber experiments and not surprisingly the number of ingested cysts is also reduced. As in the previous cases among polyp effects make the greatest contribution to total variance. In the ANOVA neither the effects of current speed nor up/ downstream positioning are significant. There is, however, a significant time effect - mean numbers of ingested cysts increasing with time. Increases in mean
Table 4. Briarium abestinum. Number of Artemia cysts ingested per polyp in flow tank experiments

\begin{tabular}{|c|c|c|c|c|}
\hline \multirow{3}{*}{$\begin{array}{l}\text { Current } \\
\text { speed }\end{array}$} & \multicolumn{4}{|c|}{ Length of experiment } \\
\hline & \multicolumn{2}{|c|}{$15 \mathrm{~min}$} & \multicolumn{2}{|c|}{$60 \mathrm{~min}$} \\
\hline & Upstream & $\begin{array}{l}\text { Down- } \\
\text { stream }\end{array}$ & Upstream & $\begin{array}{l}\text { Down- } \\
\text { stream }\end{array}$ \\
\hline \multirow{7}{*}{$3.5 \mathrm{~cm} \mathrm{~s}^{-1}$} & 0.0 & 0.0 & & \\
\hline & 0.0 & 0.0 & 0.10 & 0.05 \\
\hline & 0.0 & 0.0 & 0.35 & 0.65 \\
\hline & 0.05 & 0.05 & 0.35 & 0.50 \\
\hline & 0.05 & 0.0 & 0.10 & 0.30 \\
\hline & 0.40 & 0.60 & 0.70 & 0.05 \\
\hline & 0.15 & 0.45 & 0.05 & 0.0 \\
\hline \multirow{6}{*}{$7.3 \mathrm{~cm} \mathrm{~s}^{-1}$} & 0.09 & 0.16 & 0.28 & 0.26 \\
\hline & 0.10 & 0.45 & 0.0 & 0.10 \\
\hline & 0.0 & 0.0 & 0.55 & 1.50 \\
\hline & 0.05 & 0.03 & 0.05 & 0.05 \\
\hline & 0.0 & 0.05 & 0.30 & 1.30 \\
\hline & 0.05 & 0.0 & 0.10 & 0.30 \\
\hline $\bar{X}$ & 0.04 & 0.11 & 0.18 & 0.54 \\
\hline
\end{tabular}

numbers of ingested cysts with time can be attributed to either an increase in the number of particles ingested by polyps which feed or to the proportion of polyps which capture cysts. No significant differences were observed in the number of cysts in polyps which fed. However, the proportion of polyps capturing prey in the $3.5 \mathrm{cms}^{-1}-60$ min treatment is greater than that in either of the $15 \mathrm{~min}$ treatments $(\mathrm{P}<0.05$, STP test with Mann Whitney U test; Sokal and Rohlf, 1969). A pairwise comparison of ingestion rates on upstream and downstream sides of branches indicates that ingestion is greater on the downstream side of the branch (Wilcoxon matched pairs test, $\mathrm{P}<0.05$ ).

\section{DISCUSSION}

Polyp behavior during night-illumination experiments is best described as a feeding response. However, samples collected at the completion of these experiments were uniformly devoid of ingested prey. The technique of preserving specimens in situ at the finish of the experiment precludes the possibility of prey regurgitation and immediate preservation precludes digestion and/or internal redistribution of prey. The conclusion therefore is that the species tested were incapable of capturing zooplankton attracted to the dive lights.

Some gorgonians are capable of capturing zooplankton in experimental situations (Leversee, 1977). However, Artemia nauplii - used in these experiments - are small, slow-moving prey. The zooplankters attracted to 
dive lights are usually larger and faster. Microscopic examination of sections from specimens collected in this study ( $E$. Peters, pers. comm.) indicate that these species, like those studied by Mariscal and Bigger (1977), have reduced nematocyst densities. Given the dramatically reduced nematocyst densities of these gorgonians, it is not surprising that large zooplankters readily escape. In similar experiments with scleractinian corals like Moptastrea cavernosa and Colpophyllia natans zooplankters attracted by dive lights are frequently captured. The gorgonians inability to capture large zooplankters is best explained by their reduced cnidom. The effect of this on feeding in nature is to limit their prey to only a small fraction of the total zooplankton population. It is also probable that gorgonians capture fewer of the smaller prey than scleractinians even though these prey are more easily captured.

Although the species examined in this study do not readily capture zooplankton, these gorginians are capable of capturing and ingesting non-motile prey (Artemia cysts). All 3 species readily ingested cysts, but not all exhibited equivalent abilities to do so. Even 2 colonies of the same species were found to differ in their feeding capacity.

Several authors have discussed models of feeding in organisms like gorgonians (Porter, 1976; Koehl, 1977; Leversee, 1976; Rubenstein and Koehl, 1977; Sebens, 1979). These models employ as variables size of the tentacle, current speed, particle size, size of the polyp, number of polyps, and orientation of feeding structure. Changes in any of these parameters will change the efficiency with which a given prey particle is utilized. Similarly, differences in a coelenterates cnidom will also affect capture efficiency. Many of these factors vary among the species examined in this study and it is of interest to compare the results of this study with those predicted by other authors.

Porter (1976) and Sebens (1979) both predict a positive correlation between size of polyps and zooplankton capture. This relationship is based on a simple interception model in which the number of captured prey is proportional to the surface area of the capture organ. Size of the capture surface may also effect the size range of particles which may be captured (Sebens, 1979) and similar limitations will be exerted by differences in the cnidom. Among organisms with a similar cnidom and for a particle of set size (i.e. an Artemia cyst) the relationship of capture surface to capture rate should hold. The true capture area of a gorgonian polyp is not characterized by the polyp diameter but rather by the diameter of the polyp plus its expanded tentacles. Using this as an index, the capture surfaces of polyps of the four specimens in this study can be ranked Briarium abestinum $>$ Pseudoplexaura porosa $\mathrm{A} \approx P$. porosa $\mathrm{B} \gg$ Pseudopterogoria americana. This ranking bears little resemblance to the ranking based upon cyst ingestion rates. B. absentinum, the species with the largest capture area per polyp, has the lowest ingestion rate and its polyps even ingest fewer cysts than the much smaller P. americana polyps. Even more striking is the significant feeding difference observed between the two $P$. porosa colonies which have virtually identical polyps.

This lack of correspondence between observed and predicted ingestion rates most likely reflects the complexity of the feeding process. The capture surface model relies on a simple impact-capture sequence in which the probability of a particle striking a polyp is a function of the capture surface area and capture is a constant proportion of all intercepted prey. As has already been noted, differences in the cnidom affect the proportion of prey which are actually subdued and ingested. Given inter-specific differences in the cnidom, this model still predicts that captures among polyps of the same colony will follow a Poisson distribution. In the experiments reported here captures did not follow a Poisson distribution. All polyps apparently do not have an equal chance at capturing prey.

Differences among polyps on the same branch may relate to modes of particle capture not directly related to tentacular size. Some gorgonians, like Pseudopterogorgia americana, produce copious quantities of mucus. This mucus may be involved in capture via mucus nets (Lewis and Price, 1976). In such a case ingestion of prey would not be random. Furthermore, the presence of this mucus may increase the proportion of intercepted particles ingested. This effect would explain the surprisingly high cyst-ingestion rates of $P$. americana.

Additional mechanisms for non-random distributions of capture events are illustrated by the flow tank experiments. In these experiments polyps on the downstream side of branches captured greater numbers of prey than on the upstream side. Briarium abestinum has relatively few nemotocysts. Consequently, adhesion of a captured particle to the tentacle is most probably related to the 'stickiness' of the mucus. In the higher flow regime of the upstream side, intercepted particles may be stripped from the tentacles before they can be ingested. Instances of such 'escapes' were frequently observed in the flow tank experiments. Additionally polyps on the upstream surface of the branch are deformed by the current. Leversee (1976) hypothesized that in strong current, polyps of Leptogorgia colonies were 'bent over' and fed primarily on the downstream side of the colony. In Briarium the branch is thick and forward facing; polyps may simply be deformed so that they are unable to feed. Finally, eddies on the downstream side may result in reduced currents allowing more efficient capture and also may 
result in small localized concentrations of prey. Porter (1979), for instance, observed increased feeding on the downstream sides of Montastrea cavernosa colonies.

When compared to other reef anthozoans, the range of morphologies exhibited by these 3 gorgonian species is small, and their zooplankton-feeding abilities were indeed predictable from their cnidom. However, differences among these species are not easily explained by morphology alone. Detailed studies may explain some of the variance. However, as evidenced by the differences among Pseudoplexaura porosa colonies, factors not included in many existing models may account for much of the variance in gorgonian feeding rates.

Acknowledgements. The research reported was conducted during a Rosenstiel Post-doctoral Fellowship at the University of Miami, USA. I thank D. L. Taylor for the use of equipment. Data on nematocyst densities were made available by $\mathrm{E}$. Peters (University of Rhode Island).

\section{LITERATURE CITED}

Disalvo, L. H. (1971). Ingestion and assimilation of bacteria by two scleractinian coral species. In: Lenhoff, H. M., Muscatine, L., Davis, L. V. (eds) Experimental coelenterate biology. University of Hawaii Press, Honolulu, pp. 129-139

Ducklow, H. W., Mitchell, R. (1979a). Bacterial populations and adaptations in the mucus layers of living corals. Limnol. Oceanogr 24:715-725

Ducklow, H. W., Mitchell, R. (1976b). Composition of mucus released by coral reef coelenterates. Limnol. Oceanogr. 24: 706-714

Glynn, P. W. (1973). Ecology of a Caribbean coral reef. The Porites reef-flat biotopye. Part II. Plankton community with evidence for depletion. Mar. Biol. 22: 1-21

Gust, G. (1977). Turbulence and waves inside flexible-wall systems designed for biological studies. Mar. Biol. 42: $47-53$

Johannes, R. D. (1967). Ecology of organic aggregates in the vicinity of a coral reef. Limnol. Oceanogr 12:189-195

Johannes, R. D., Coles, S. L., Kuenzel, N. T (1970). The role of zooplankton in the nutrition of some scleractinian corals. Limnol. Oceanogr. 15: 579-586

Koehl, M. A. R. (1977). Water flow and the morphology of zoanthid colonies. In: Proceedings of the third international coral reef symposium, Vol. I. University of Miami, Florida, USA, pp. 437-444

Leversee, J. (1976). Flow and feeding in fan shaped colonies of the octocoral, Leptogorgia virgulata. Biol. Bull. mar biol. Lab, Woods Hole 151: 344-356

Lewis, J. B. (1976). Experimental tests of suspension feeding in Atlantic reef corals. Mar. Biol. 36: 147-150

Lewis, J. B., Price, W. S. (1975). Feeding mechanisms and feeding strategies of Atlantic reef corals. J. Zool., Lond. 176: $527-544$

Mariscal, R. N., Bigger, C. H. (1977). Possible ecological significance of octocoral epithelial ultrastructure. In: Proceedings of the third international coral reef symposium, Vol. 1. University of Miami, Florida, USA, pp. 127-134

Marshall, N. (1968). Observations on organic aggregates in the vicinity of coral reefs. Mar. Biol. 2: 50-53

Murdock, G. R. (1978). Circulation and digestion of food in the gastrovascular system of a gorgonian octocoral (Chidaria, Anthozod). Bull. mar. Sci. 28: 363-370

Muscatine, L., Hand, C. (1958). Direct evidence for the transfer of materials from symbiotic algae to the tissues of a coenenterate. Proc. natn. Acad. Sci., U.S.A. 44: 1259-1263

Porter, J. W. (1976). Autotrophy and heterotrophy and resource partitioning in Caribbean reef building corals. Am. Nat. 110: 731-742

Porter, J. W. (1979). Adaptive geometry of zooplankton-feeding in reef corals. (abstract) Abstr. Pap., 42 A. Meet. Am. Soc. Limnol. Oceanogr

Roushdy, H. M., Hansen, V. K. (1961). Filtration of phytoplankton by the octocoral Alcyonium digitatum L. Nature, Lond. 190: 649-650

Rubenstein, D. I., Koehl, M. A. R. (1977). The mechanisms of filter feeding: some theoretical considerations. Am. Nat. 110: 981-994

Rublee, P. A., Lasker, H. R., Gottfried, M., Roman, M. R. (1980). Production and bacterial colonization of mucus from the soft coral Briarium abestinum. Bull. mar. Sci. 30: 888-893

Sebens, K. P. (1979). The energetics of asexual reproduction and colony formation in benthic marine invertebrates. Am. Zool. 19: 683-697

Stephens, G. C. (1962). Uptake of organic material by aquatic invertebrates. I. Uptake of glucose by the solitary coral Fungia scataria. Biol. Bull. mar. biol. Lab., Woods Hole 123: $648-659$ 